\title{
Using mixed methods to understand sensitive wildlife poisoning behaviours in northern Cambodia
}

\author{
Emiel De Lange, E. J. Milner-Gulland, Vichet Yim \\ Chantheavy Leng, Sithan Phann and Aidan Keane
}

\begin{abstract}
In northern Cambodia, threatened wildlife, livestock and people are being poisoned by pesticides deposited in seasonal waterholes. Addressing this critical conservation threat requires understanding the drivers of poisoning behaviours and the social contexts in which they occur. This study across 10 communities in two protected areas aimed to provide a first assessment of this phenomenon. We used the theory of planned behaviour to measure socio-psychological determinants of behaviour and deepened this understanding using informant interviews and focus group discussions. Informants reported that so-called termite poisons, including powerful carbamates, are deliberately deposited at waterholes to catch wildlife for consumption. This method is perceived to be low effort and high efficacy, and perceptions of the health risks vary. Predominant users are young men and children, but it is unclear whether the practice is related to food insecurity. Threatened wildlife species reported as affected include the giant ibis Pseudibis gigantea and vulture species. Overall, social norms are strongly negative towards poisoning; $75 \%$ of survey respondents perceived negative norms because of impacts on human and livestock health, environmental quality, and risks of legal sanctions. This has led to interventions by local authorities in half of the studied villages. We suggest that future interventions should raise the salience of negative norms by providing a non-conflictual mechanism for community members to participate in monitoring and sanctioning, such as a reporting hotline. Regulatory interventions are also required to control the supply of restricted pesticides.
\end{abstract}

EMIEL DE LANGE* (Corresponding author, (1) orcid.org/0000-0002-5853-3657) Institute of Geography, School of Geosciences, 1 Drummond Street, EH8 9XP, Edinburgh, UK. E-mail e.delange@ed.ac.uk

E. J. Milner-Gulland (1D orcid.org/0000-0003-0324-2710) Department of Zoology, Interdisciplinary Centre for Conservation Science, University of Oxford, Oxford, UK

Vichet Y Im Royal University of Agriculture, Phnom Penh, Cambodia

Chantheavy Leng ${ }^{\dagger}$ Sansom Mlup Prey, Phnom Penh, Cambodia

Sithan Phann Wildlife Conservation Society, Phnom Penh, Cambodia

AidAN KeANE (ㅇ) orcid.org/0000-0002-9704-5576) University of Edinburgh Edinburgh, UK

${ }^{*}$ Also at: Department of Zoology, Interdisciplinary Centre for Conservation Science, University of Oxford, Oxford, UK

${ }^{\dagger}$ Also at: Royal University of Agriculture, Phnom Penh, Cambodia

Received 19 November 2019. Revision requested 9 December 2019.

Accepted 17 December 2019. First published online 29 October 2020.
Keywords Behaviour change, bushmeat, hunting, illegal behaviour, mixed methods, pesticide misuse, theory of planned behaviour, wildlife poisoning

Supplementary material for this article is available at doi.org/10.1017/So030605319001492

\section{Introduction}

Toxic agrochemicals are a major threat to wildlife, lead1 ing to widespread declines in insect and bird populations (Carson, 1962), and deaths of larger animals (Berny, 2007). Deliberate poisoning of large animals is also widespread (Richards, 2011); e.g. in Africa, some farmers use carbofuran pesticides to kill predators (Ogada, 2014), driving a crash in vulture populations (Buechley \& Șekercioğlu, 2016; Ogada et al., 2016). However, the use of agrochemicals for harvesting wild meat has rarely been documented (e.g. Odino, 2011).

In 2015, five seasonal waterholes (trapeangs) in Cambodia's Preah Vihear province were found to contain carbofuran. Threatened wildlife species found dead included Critically Endangered vultures, and people fell ill after drinking contaminated water (Plate 1; Wildlife Conservation Society, 2016; Loveridge et al., 2019). Although reports of suspected wildlife poisonings in Cambodia are common, including 51 suspected vulture poisonings during 2004-2015 (Loveridge et al., 2019), these were the first records of poisoned waterholes with toxicological confirmation. Because of the potentially critical threat to human health and populations of threatened wildlife, conservation groups took immediate action based on assumptions about poisoning, including awareness-raising meetings in local communities, and producing educational media (Loveridge et al., 2019). To inform intervention design, this study aims to provide a broad assessment of waterhole poisoning in Preah Vihear province: identifying the actors involved, understanding their motivations and describing the social context in which poisoning occurs.

Cambodia has been described as a dumping ground for unwanted pesticides because of weak regulation of imports (imports increased 17-fold during 2002-2012; Matsukawa et al., 2016) and sale (EJF, 2002). For example, although Cambodia is signatory to international conventions restricting carbofuran use, this pesticide remains widely used (Rotterdam Convention, 2013; Matsukawa et al., 2016). 


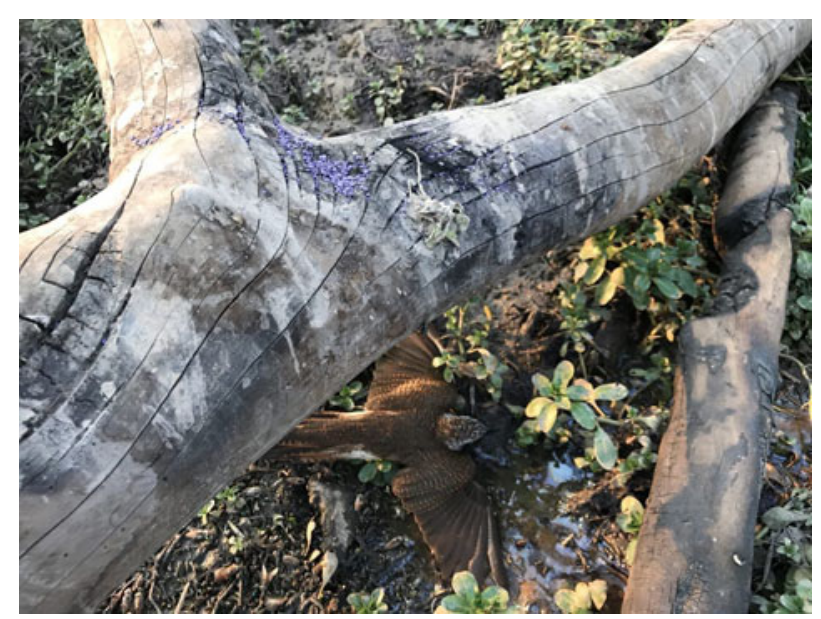

Plate 1 Waterhole poisoning, showing a dead plaintive cuckoo Cacomantis merulinus close to the water. A purple granular pesticide is visible on the fallen tree. Photo: Wildlife Conservation Society Cambodia.

Inadequate education and labelling mean that pesticide misuse is widespread, and poisoning of farmers, both acute and chronic, is common (EJF, 2002). Researchers have suggested that misuse, accidental run-off and intentional poisoning are affecting fish and wildlife populations at a national scale (Saroeun, 1999).

Effectively addressing wildlife poisoning requires understanding the specific practices and actors involved, their motivations and attitudes (St John et al., 2013), and the social context (St John et al., 2010). Local NGO workers have suggested that waterhole poisoning could be an unintended consequence of agriculture, a result of conflicts such as land disputes, or intentional wildlife killing. Each practice may have multiple interacting drivers. For example, intentional wildlife poisoning could be driven by socio-cultural demand for wild meat (Delisle et al., 2018) or by economic incentives to supply wildlife products to market (MilnerGulland et al., 2003). It may also be employed as an act of resistance against conservation authorities (Norgrove \& Hulme, 2006; Peterson et al., 2017).

Theory from social psychology can guide research on human behaviour. The theory of planned behaviour (Fig. 1) has been widely used to understand the sociopsychological determinants of conservation behaviours (St John et al., 2010; Ward et al., 2018). This theory posits that an individual's intention to carry out a behaviour in a particular context is predicted by that individual's attitudes (i.e. is it a good thing to do?), perceptions of social norms (i.e. do others do it?), and perceived control over the behaviour (i.e. am I able to use this method?). It assumes that these are semi-stable constructs that can be reliably determined by measuring relevant salient beliefs (Ajzen, 1991). The theory of planned behaviour can inform the design of behaviour change interventions (Hardeman et al., 2002; Michie et al.,
2008). For example, there may be multiple actors with different psychological determinants, requiring multi-faceted interventions that segment audiences (Mckenzie-Mohr, 2000; Jones et al., 2019; Travers et al., 2019). Where individual behaviours are constrained or enabled by external factors, conservationists may additionally intervene at higher levels, such as by influencing economic drivers (McKenzie-Mohr \& Schultz, 2014).

To inform intervention design, our study set out to understand waterhole poisoning across two protected areas in Preah Vihear, using a mixed-methods approach. We aimed to quantify the prevalence of relevant practices and measure variables from the theory of planned behaviour to unpack socio-psychological drivers. We collected qualitative data on poisoning practices to contextualize our quantitative data, and to determine the motivations of poisoners and the social contexts in which poisoning occurs.

\section{Study area}

Preah Vihear province in northern Cambodia lies in a global biodiversity hotspot (Myers et al., 2000), contains the largest remaining mosaics of forests and grassland in mainland South-east Asia and is home to 28 Critically Endangered or Endangered species (Clements et al., 2010), including the giant ibis Pseudibis gigantea, white-shouldered ibis Pseudibis davisoni and three vulture species. Many rely on waterholes for food and water throughout the dry season (Pin et al., 2020). At the time of this study, two protected areas were managed by the Ministry of Environment (a third was gazetted in late 2017; Fig. 2), with support from the Wildlife Conservation Society: Chheb and Kulen Promtep Wildlife Sanctuaries.

We conducted our study across the two protected areas in 10 villages that reflect a cross-section of levels of wealth, access to markets, and involvement in conservation programmes. All were involved in previous research (Beauchamp et al., 2018a,c, 2019). Many originated from small groups of Indigenous communities, Khmer Rouge soldiers, or other fugitives, living in the remote forest. After the Royal Government recaptured this area from the Khmer Rouge in the late 1990s the state consolidated control over the region through mass patronage and infrastructure development. Cambodia's political system is described as hegemonic authoritarianism and the government closely monitors rural life and political activity (Craig \& Kimchoeun, 2011; Beban et al., 2019; Morgenbesser, 2019).

Cambodia has liberalized its economy, with GDP growth averaging $8.7 \%$ per year (Hughes \& Un, 2011). Although this has led to increased employment opportunities and improved access to markets, for many residents it has led to dispossession of agricultural land and nearby forests by corporate interests with state backing, and migration of landless people from other provinces (Davis et al., 2015; Milne, 2015; Beauchamp 


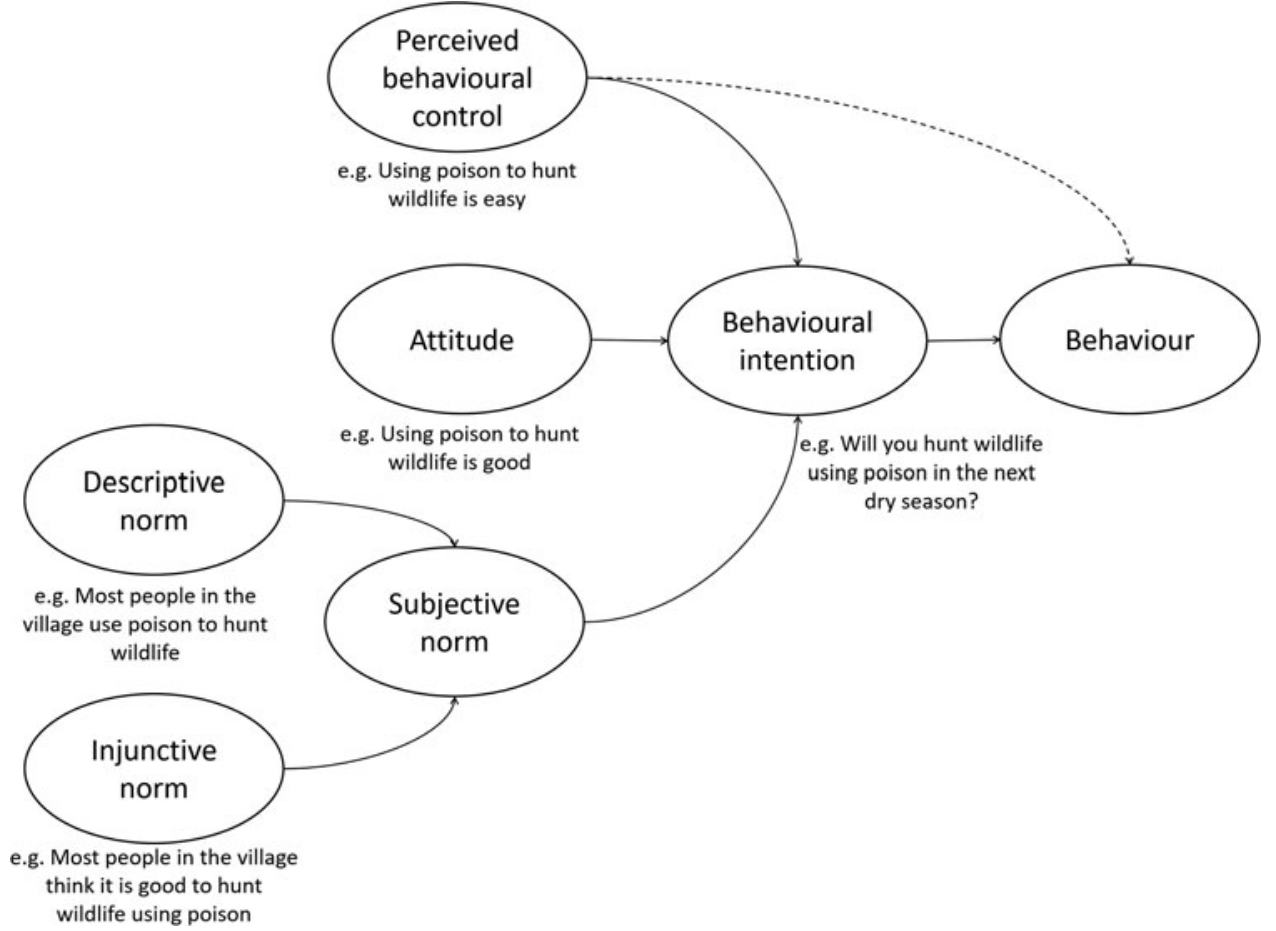

FIG. 1 A summary of the theory of planned behaviour (Ajzen, 1991) as applied in this study. Within the theory an individual's behaviour is predicted by their intention, which in turn is influenced by their attitudes towards the behaviour, their perceived control over the behaviour, and their perception of social norms related to the behaviour. The subjective norm is influenced by descriptive (how others behave) and injunctive norms (how others think one ought to behave). et al., 2018b). Given these pressures and opportunities, many residents who previously farmed subsistence rice now clear forest and accumulate land, to grow and sell cash-crops such as cassava or cashew, or to take advantage of rising land prices (Beauchamp et al., 2018a). Clearing land within the protected areas is illegal, but is facilitated or promoted by personal relationships with local officials (Milne, 2015). Cambodian society is marked by neopatrimonialism: power is exercised through personalized patron-client relations, with an emphasis on kinship. A village is a geographical collection of relatively autonomous households and much interaction is governed by norms of reciprocity (Ovesen et al., 1996; Ledgerwood \& Vijghen, 2002; Sedara, 2011). Each village has a chief who is either appointed by the state or nominated by village elites. Chiefs vary in influence, and they tend to be loyal party members who participate in surveillance and disciplining of the community (including researchers). Their bureaucratic position gives them power to mediate access to the state (i.e. registration of land titles), but some may enjoy respect for facilitating the community's interests (Ledgerwood \& Vijghen, 2002; Biddulph, 2015). Other disputes may be settled through informal processes by village elders (Luco, 2002; Travers et al., 2011).

The Ministry of Environment and the Wildlife Conservation Society support village institutions and conservation programmes in most communities within the protected areas. Participatory land-use plans have been developed with residential, conservation, agricultural and other zones. Community protected area or community forest committees are elected in nine of the 10 villages, to monitor and enforce compliance with these rules. To incentivize compliance, the Ibis Rice company buys rice at a premium from farmers who follow conservation rules (including no hunting and no use of pesticides; Clements et al., 2010). Village market network committees are elected to monitor farmers' compliance and determine eligibility in five of the villages. There are also community-managed ecotourism projects in three villages that generate village development funds and direct payments to individuals to protect the nests of priority birds (Clements et al., 2010; Clements \& Milner-Gulland, 2015). Medium-term evaluations show that these programmes have contributed to improved tenure security and have provided additional livelihood options (Beauchamp et al., 2018a). Law enforcement patrols are also conducted by the state.

Fish and wild meat remain important dietary components, and collection of non-timber forest products, such as liquid resin and mushrooms, provides additional income (Travers et al., 2011; Beauchamp et al., 2018a). Most households are engaged in incidental wildlife hunting for home consumption, such as setting traps around agricultural land, taking dogs into the forest when collecting mushrooms or a slingshot while fishing. This affects common species such as the water monitor Varanus salvator, muntjac Muntiacus muntjak or wild boar Sus scrofa, and is tolerated by authorities. The meat is considered preferable to domestic or market meat because it is seen as chemical-free. Only a small proportion of households practise targeted hunting in the forest using homemade guns or snares, as this requires skilled labour. They target high-value species for sale at local markets (Coad et al., 2019; Ibbett et al., 2020). 


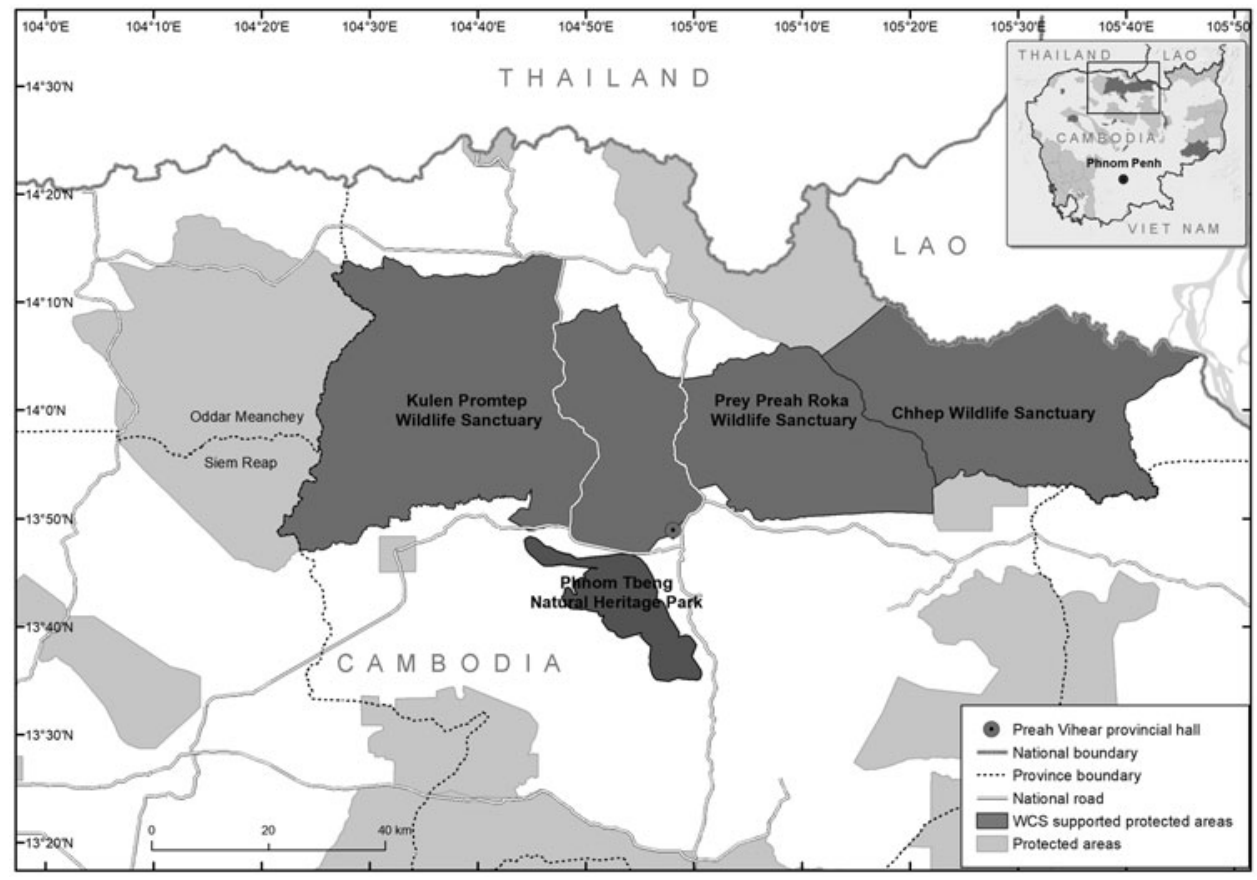

FIG. 2 Study area location in Preah Vihear province, Cambodia. The Northern Plains complex of protected areas comprises three protected areas, including the two included in this study (Kulen Promtep and Chhep Wildlife Sanctuaries).

\section{Methods}

The research team comprised students from the UK and Cambodia and operated independently of the Wildlife Conservation Society. We used unmarked vehicles and discussed our position with chiefs and other participants. Participants (all aged over 18) gave verbal consent following explanation of the research.

Exploratory pilot studies were conducted in two villages, outside the protected areas, which had been matched to our study villages (Clements \& Milner-Gulland, 2015). We used key informant interviews and focus group discussions to investigate pesticide usage. We identified salient beliefs to measure for the theory of planned behaviour and to develop the questionnaire, which was piloted with c. 30 respondents in each of the two villages, and then refined. To measure the prevalence of sensitive poisoning practices we initially used the single sample count method (Petroczi et al., 2011) but switched to the unmatched count technique for the second village because of the technique's lower cognitive demand. The surveys were initially translated into Khmer and back into English to ensure accuracy, and this was repeated following modifications.

In the full study, we administered the final survey to a sample of households, organized focus group discussions, and conducted key informant interviews in each of the 10 villages. We visited each village for c. 5 days during JulySeptember 2017, staying at the home of the village chief or a nominated subordinate. It was necessary to stay at a home for security reasons, and association with the chief was considered the best option as it is a common practice for visitors without personal contacts in the community.
This also legitimized our activities, and reassured villagers that talking to us was condoned, but may have raised concerns that responses would be shared with authorities, despite our assurances.

We administered the questionnaire to 30-60 households in each village. Sampling was opportunistic because of the unpredictable availability of household members, but we attempted to sample proportionally from all geographical sections of a village. We sought to interview male household heads as in the pilot study they were found to be most knowledgeable on the topic, but also surveyed 24 female household heads. We visited respondents at their homes and collected survey data using Open Data Kit (Brunette et al., 2013). We collected demographic and livelihood information, and used an adaptation of a basic necessities survey previously developed for the same area, to give an index of household wealth (Beauchamp et al., 2018a).

We used the unmatched count technique to estimate prevalence of sensitive wildlife poisoning practices (Hinsley et al., 2019). In each round, respondents selected one of two face-down cards. One card displayed images of four related non-sensitive behaviours. The second card was identical but included the sensitive behaviour. Without identifying which, respondents were asked to state the number of displayed behaviours they had practised in the past year. A nonsensitive practice round was used to confirm that the procedure was understood before continuing (Hinsley et al., 2019). We then asked about pest control issues and uses of pesticides identified during the pilot study. We used images of pesticide packaging collected during a market shelf survey to help respondents identify specific products. We used fivepoint Likert scales to measure constructs from the theory of 
planned behaviour related to wildlife poisoning: two items each for attitudes, perceived behavioural control, and perceptions of descriptive and injunctive norms. Finally, we directly questioned the respondent about their hunting practices, including use of poison for hunting.

Focus group discussions were organized separately for men and women in each village. We invited eight participants, selected in consultation with the village chief, but the number of attendees was 4-10. We began by asking about non-sensitive topics such as pest issues, pest control, and use of pesticides, and finally other forms of poisoning. We adapted key informant interviews depending on the specific knowledge of the informant. In each village we made efforts to interview the village chief, local doctors, shopkeepers, and leaders of conservation committees, and opportunistically interviewed other individuals. When informants indicated direct knowledge or experience of wildlife poisoning, we asked about the practice, the motivations for it, and how they had learnt this method.

Statistical analysis was performed in $R$ 3.5.2 (R Core Team, 2017). We used the List package to analyse unmatched count technique data (Blair \& Imai, 2010). We calculated estimated prevalence of each behaviour and counted the number of maximal responses (i.e. respondents stating they perform all behaviours on the card). Using the method described by Blair \& Imai (2012) we also tested for design effects: lower than expected responses from respondents who see the sensitive item, indicating dishonest responses. When theory of planned behaviour construct measures were internally consistent (i.e. Cronbach's $\alpha>0.5$ ), we summed them into single continuous measures. We fitted linear mixed models with a Gaussian or binomial response to test for associations between individual variables and beliefs, practices, perceptions, and theory of planned behaviour variables. For individual ordinal Likert measurements, we used cumulative link (logit) mixed models. Village was included as a random effect in all models. Qualitative data was translated, and transcribed into NVivo (QSR International, 2015). Text was then coded into pre-defined themes related to the research questions. New themes were also allowed to emerge from the data, following which the data were recoded. Our results subheadings reflect these themes.

In total, we interviewed 462 respondents $(20-50 \%$ of households in each village), and carried out 20 focus group discussions and 53 key informant interviews. We preserved the anonymity of the villages.

\section{Results}

\section{Waterhole poisoning practices}

During the dry season termite poison mixed with rice, water, fruit or fish, is placed in the water of a waterhole or in a container nearby, to hunt wildlife (Plate 1). One respondent summarized this as follows, and similar descriptions were provided by a total of 28 informants from eight villages, including during two focus group discussions.

In the dry season, when the waterholes are dry, I put the poison in a coconut shell. It is a powder which I dissolve in the water and put in the shell [...]. Using this poison, I used to catch a lot of birds, maybe five or six each time, and I would try three times in one season.

Termite poisons are considered the strongest chemicals available. This term referred to multiple products, identified by packaging, including carbosulphan, carbofuran, fipronil, diazinon and cypermethrin. Respondents often described the poisons by their blue, red or purple colour. Small unlabelled bags of termite poison are also available in local shops for KHR 1,000 (c. USD 0.25; Plate 2). We also recorded other misuses of pesticides (Supplementary Material 1).

\section{Prevalence}

When directly questioned, 174 respondents (38\%) stated they hunted wild meat, but only six respondents (1.3\%) admitted to poisoning waterholes (Supplementary Material 2). In the unmatched count technique, the practice round showed no design effect $(\mathrm{P}=0.67)$. The estimated prevalence of waterhole poisoning was $-40 \%$ of the population $(\mathrm{SE}=0.12, \mathrm{P}<0.01)$. This is an impossible result, and the significant design effect $(\mathrm{P}<0.01)$, suggests this occurs because respondents shown the sensitive behaviour deliberately under-report the number of activities in which they engage. Nonetheless, six respondents (2.4\%) gave a maximal response when shown the card including the sensitive behaviour, effectively indicating engagement in waterhole poisoning.

Informants in eight villages reported occurrences of waterhole poisoning. In one village the chief estimated c. $30 \%$ of households engaged in the practice, and two other informants gave estimates of $25-30 \%$. In other villages, estimates varied more widely. For example, one chief denied any poisoning, but his deputy gave an estimate of $30 \%$. In another village, some estimates varied from c. 4 to $10 \%$, and another two informants estimated $50 \%$. In the other four villages, just a few households were indicated to engage in the practice (Fig. 3). Three informants reported having practised waterhole poisoning for many years. One man admitted that he stopped poisoning 7 years ago after suffering from symptoms of poisoning and accidentally killing one of his dogs. Another told us he had learnt the method from his father who had been practising it for many years.

\section{Impacts of poisoning}

Informants and focus group discussion participants described impacts of poisoning on the environment, wildlife, 


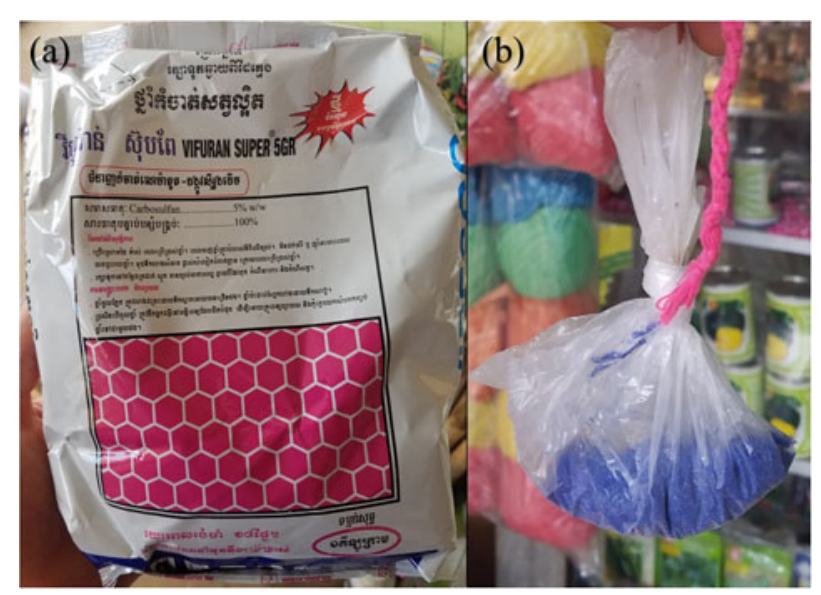

Plate 2 Packaging of one of the most commonly available 'termite poisons' as (a) sold in a provincial market, and (b) resold in a village shop. This is a carbamate, which is banned in many countries, and is restricted in Cambodia (Royal Government of Cambodia, 2012). Photo: authors.

domestic animals and human health. Concerns raised included reduced availability of clean water, and lost fishing grounds. Poisoning at waterholes was seen as indiscriminate and many informants reported seeing a wide variety of wildlife killed, including species of conservation concern (Supplementary Table 2). Many were unable to identify the species they had observed but reported seeing large numbers of dead animals.

Informants in three villages complained their dogs had been poisoned. Similarly, two village chiefs reported cattle having died after drinking poisoned water. There were widespread concerns about consuming poisoned meat; many respondents across all types of questioning gave direct or indirect accounts of symptoms, including diarrhoea, stomach aches, chest, intestinal or joint pain, fever, tiredness, hot eyes, thirst and dizziness. One traditional doctor in a village where the pilot study was conducted reported the death of a young boy who consumed poisoned meat whilst suffering malaria, although this could not be corroborated. Some respondents who admitted having used poison had stopped after suffering stomach aches, but others had not suffered any symptoms. Other informants attributed symptoms to other factors such as the meat being unwashed, or did not consider the symptoms significant. There was a widespread belief that removing the internal organs and head of the animal renders the meat safe to eat. During the pilot study, one male participant of a focus group discussion summarized these beliefs:

A few men have had stomach aches after eating poisoned birds, but they continue to eat. It is of low concern, and they avoid eating the internal organs for this reason [...]. Some who have experienced this have switched to using nets, but not all [...]. The stomach pain is mild and happens after a lot of meat is eaten, there is no diarrhoea [...]. They don't worry enough to go to the doctor, and not even all men experience this.

\section{Motivations and key actors}

Most reports were of villagers using poison to catch food for household consumption, including six individuals (participants of one focus group discussion) who had themselves engaged in poisoning, and almost all of the 34 informants who had indirect knowledge of poisoning. Informants in three villages explicitly denied the existence of trade in poisoned meat when asked, but one informant reported that trade with the nearest market was occurring, and another described trade occurring within another village. Sharing surplus poisoned meat with relatives and neighbours was more common. Further reports from two villages indicated that workers from nearby agro-industry concessions used poison to defend crops from cattle encroachment. Similarly, in one focus group discussion participants implicated soldiers stationed nearby. One chief suggested that poisoning may be done in retaliation, or out of jealousy, by conservation rulebreakers who had been excluded from the benefits of conservation programmes.

Most informants stated that poisoning is practised predominantly by young men of up to c. 30 years of age, to provide meat for their families. Some informants suggested that poorer households are more likely to use this method. For example, one male informant explained the motivations of a friend: 'He had no work and is poor, and wanted to eat meat.'

Other informants suggested that wealthier households were also likely to use the method, one explaining that poison was too expensive for him. From four villages we obtained reports that children older than c. 12 years were using poison. We spoke to a mother who admitted that her children used this method and were taught by a shopkeeper. Although she did not condone the practice, the family shared the meat within the household. Shopkeepers may be a source of knowledge about these methods. Informants reported that adults may also learn the method from sellers at local markets, through personal experimentation, or from other villagers. For example, one informant learnt the method from his father, who in turn was taught by a neighbour.

\section{Village perceptions}

During one pilot focus group discussion, poisoning was discussed openly, and multiple male participants admitted to practising it. In this village, informants and discussants claimed that wildlife poisoning was not illegal and spoke in detail about the practice. Participants claimed they discussed this practice with each other and learnt from each other, such as when eating wild meat at a relatives' home and enquiring about its origin or asking acquaintances about their dinner plans. Others knew not to catch fish at poisoned waterholes. Half of participants had practised 


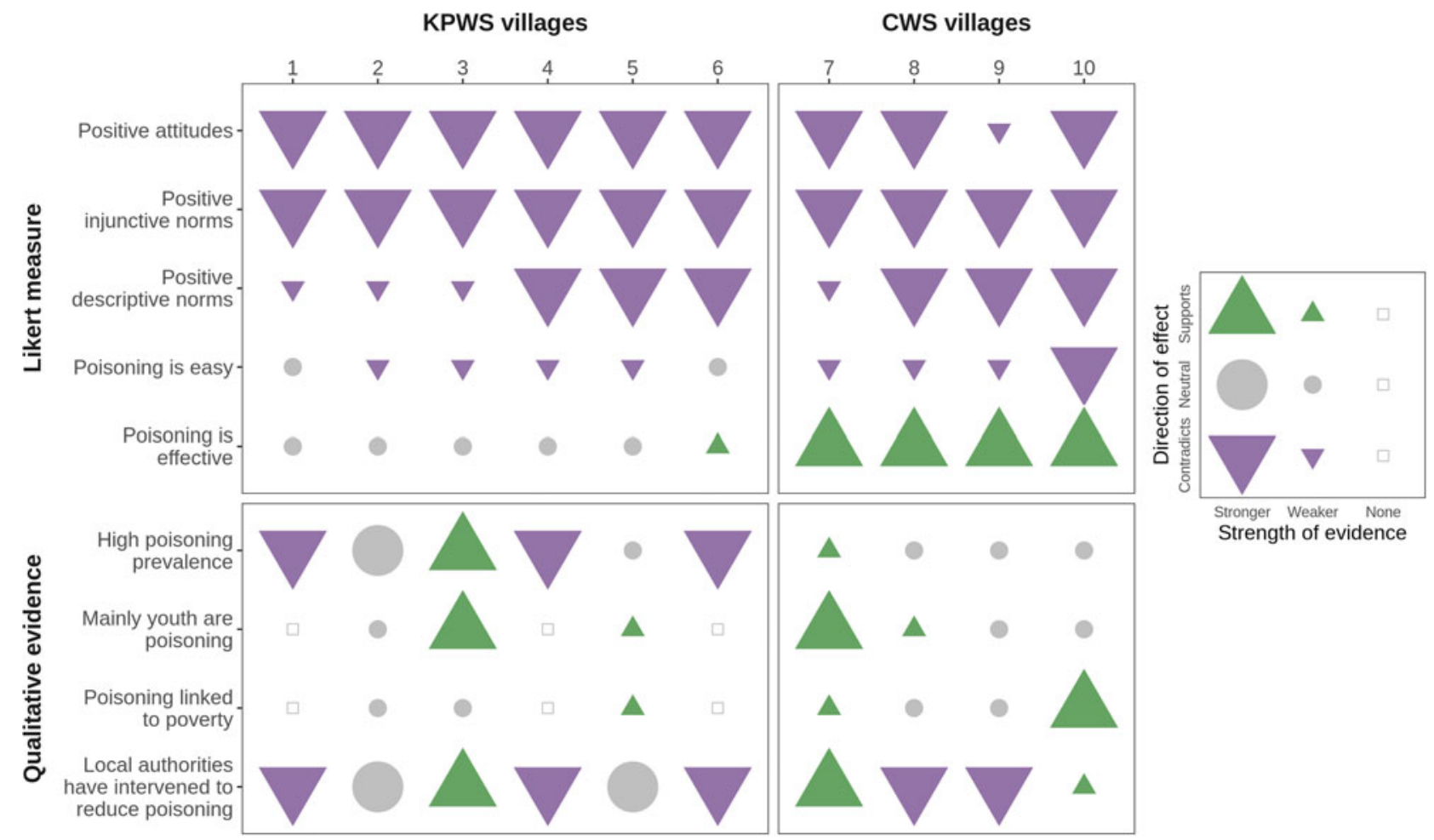

FIG. 3 The strength of evidence to support each statement or research question across all 10 villages. Villages 1-6 are in Kulen Promtep Wildlife Sanctuary (KPWS), and villages 7-10 in Chhep Wildlife Sanctuary (CWS). Triangles pointing downward indicate that the evidence contradicts, circles indicate that the evidence is neutral, and triangles pointing upward indicate that the evidence is in support of the statement on the left. Larger shapes indicate that the evidence is stronger for this conclusion. Blank squares indicate that the conclusion is not applicable (i.e. because poisoning is not thought to occur in a particular village) or that there is no evidence related to the statement. The top five rows are based on quantitative measurements using Likert scales. Evidence is considered weak if the SD overlaps with the centre of the next category (e.g. mean attitude is negative, but SD overlaps with centre of the neutral category). The bottom four rows are based on qualitative evidence, and subjective judgement of the evidence. Evidence is considered strong if more than three independent sources confirmed it.

poisoning, and other informants gave prevalence estimates as high as $70 \%$, but many had decided to switch to nets because of health concerns.

Poisoning was only acknowledged in three of the 20 focus group discussions within the protected areas, as something done by other villagers or by outsiders. In remaining focus group discussions, participants claimed to know nothing about poisoning and discussions were generally characterized by low levels of disagreement, perhaps reflecting pressures to produce socially-acceptable responses. This occurred in villages where other informants reported poisoning to be common. In one case such an informant was participating in the focus group discussion but remained silent on this point. We elicited views about waterhole poisoning on a hypothetical basis. For example, in one discussion participants claimed not to know about poisoning but suggested that if it were happening, it would be done in secret to avoid legal repercussions. When asked who else might disapprove of the practice, a male participant stated: 'If people in the village knew this was happening, they would be unhappy as it could kill their cattle'.
In the same village, multiple informants indicated that poisoning was occurring, and the chief reported having raised the issue at a meeting. The chief estimated that c. $30 \%$ of households used poison, but that they 'are not among [his] friends'. One young man informed us that a lot of people in the village are unhappy about the practice. A woman in this village told us: 'Everyone in the village knows this happens and many people don't even like using pesticides on their crops but will poison animals'.

In another village, one male informant reported that poisoning was widespread in the past, but that now only c. 50\% of the village continued to use this method. He suggested that those who had stopped became concerned about the health effects and were unhappy about the risk posed to livestock. Another man gave a similar estimate for prevalence and believed that although most others might refuse to buy poisoned meat because of health concerns, they do not mind that it occurs and prefer to avoid arguments. Nevertheless, some are unhappy about lost access to waterhole fisheries. The chief downplayed the prevalence of poisoning as just 'four or five households' and stated that it never led to arguments. 


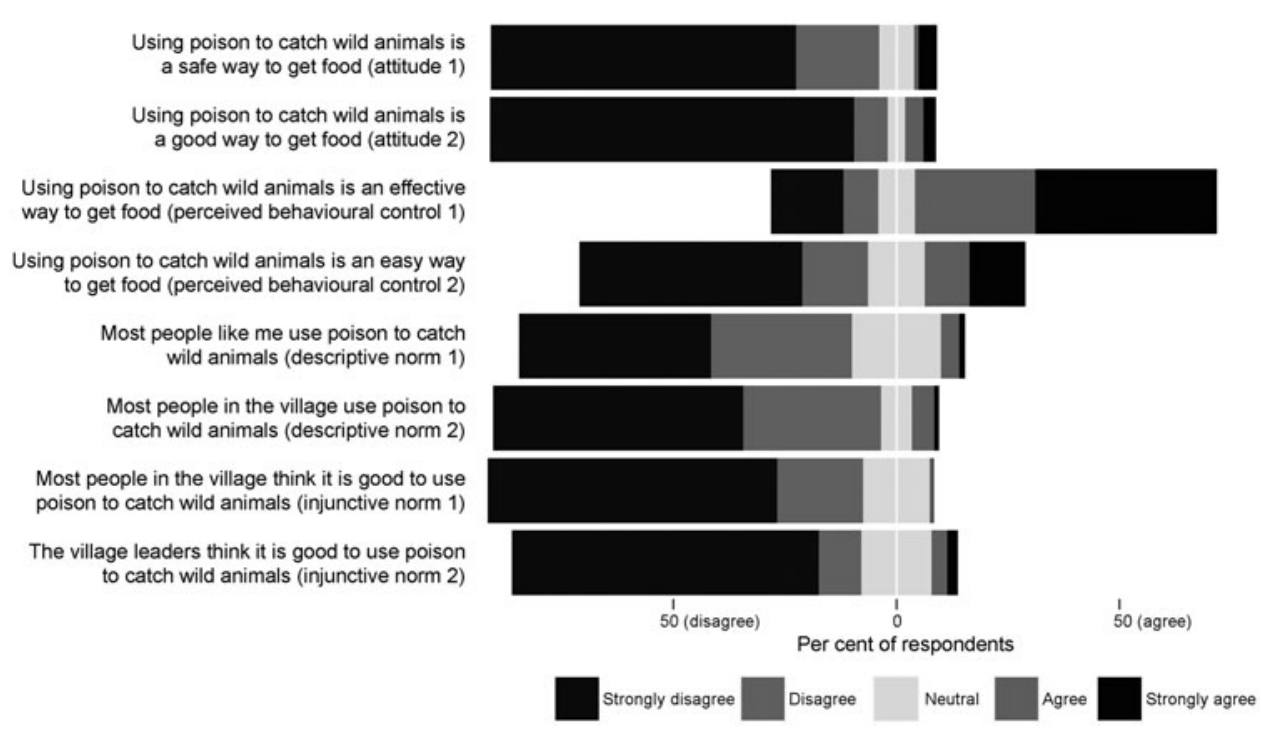

FIG. 4 Each construct from the theory of planned behaviour (attitudes, perceived behavioural control, injunctive norms, and descriptive norms) was measured using two questions on a five-point Likert scale. The respondent was presented with a statement and asked to what extent they agreed or disagreed. The per cent of 462 respondents providing each answer for each statement is shown.

\section{Attitudes, perceptions and beliefs}

Attitudes The survey data showed that hunting with poisons was regarded as unsafe by $87 \%$ and not viewed as a good method by $89 \%$ of respondents (Fig. 4). Nonetheless, 32 respondents from across all villages stated that it was a good method. The two Likert items measuring attitudes were internally consistent (Cronbach's $\alpha=0.51$ ) and were combined into a single measure. Wealthier respondents tended to have more negative attitudes, but no other variables had significant effects (Fig. 5, Supplementary Table 3). Of 168 self-reported hunters asked to explain why they did not use poison, concerns for safety and health were the most frequent response (63\%; Fig. 6), with lack of knowledge about the practice second $(20 \%)$.

Perceived behavioural control Likert measures for perceived behavioural control were not consistent (Cronbach's $\alpha=0.09$ ), so these were analysed separately: $65 \%$ of respondents did not think poisoning was an easy (sruol) method, and $13 \%$ did not know if it was easy. Wealth, agricultural pesticide use, and membership of the village market network correlated positively with perceived ease of use, whereas age and length of local residence correlated negatively (Fig. 7 , Supplementary Table 4). Agricultural pesticide use (effect $=$ $0.82 \pm$ SE 0.25 ) had the largest effect. Conversely, $68 \%$ of respondents stated that poisoning is an effective method for catching wildlife, especially younger people and those using agricultural pesticides (effect $=0.61 \pm$ SE 0.28 ). Respondents living in Kulen Promtep Wildlife Sanctuary were more likely to perceive it as effective (effect $=1.63 \pm \mathrm{SE} 0.50$; Fig. 3 , Supplementary Table 5). Informants from four villages (three in Kulen Promtep Wildlife Sanctuary, one in Chheb Wildlife Sanctuary) referred to the efficacy of poisoning as an advantage and a potential reason for others to practise it. This included the ease with which the method can be learnt and applied, the effectiveness and speed with which animals are killed, and the quantity of wildlife that can be harvested. Two informants also made favourable comparisons to guns and slingshots. Small amounts of termite poison are cheaply available locally, and several respondents suggested this made it accessible to even the poorest.

Perceived social norms Over $75 \%$ of respondents indicated anti- or non-poisoning norms for each of the four Likert items, and average responses did not vary by village (Fig. 3). Nevertheless, 28 respondents (6\%), 17 of whom resided in two villages in Chheb Wildlife Sanctuary, perceived wildlife poisoning to be a common practice in their community. The four Likert items were internally consistent (Cronbach's $\alpha=0.61$ ) and were analysed together. Older respondents and those living in Kulen Promtep Wildlife Sanctuary (effect $=-1.89 \pm$ SE 0.24 ) were more likely to perceive norms as being anti-poisoning (Fig. 5, Supplementary Table 3). Furthermore, when descriptive and injunctive norms were analysed separately, differences emerged: wealth had a small positive effect (effect $=0.15 \pm$ SE 0.06) on descriptive norms (i.e. wealthier people were more likely to think poisoning is common in the village), but in villages where local authorities had taken action against poisoning (effect $=0.48 \pm \mathrm{SE} 0.15$ ), wealth had a negative correlation with perceptions of injunctive norms (i.e. wealthier people were more likely to say that other villagers did not approve).

\section{Perceived and actual repercussions}

According to informants and focus group discussions, hunters carry out poisoning in secret, which they suggested may 


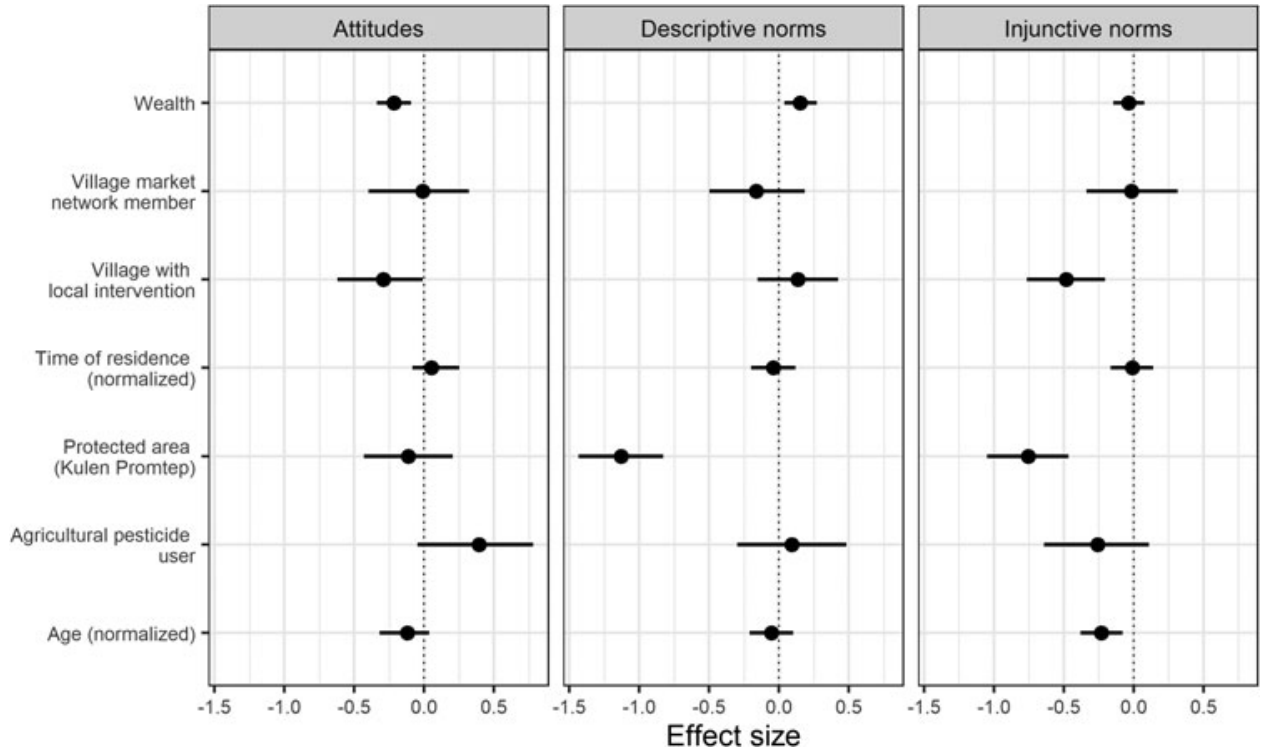

FIG. 5 We fit generalized linear models to understand which variables predict constructs from the theory of planned behaviour. This figure shows the effect sizes of several variables on attitudes, descriptive norms and injunctive norms. The bars represent 95\% confidence intervals. Intercept values are 4.080 for attitudes, 3.857 for descriptive norms, and 4.605 for injunctive norms. Normalized variables have been divided by their standard deviation.

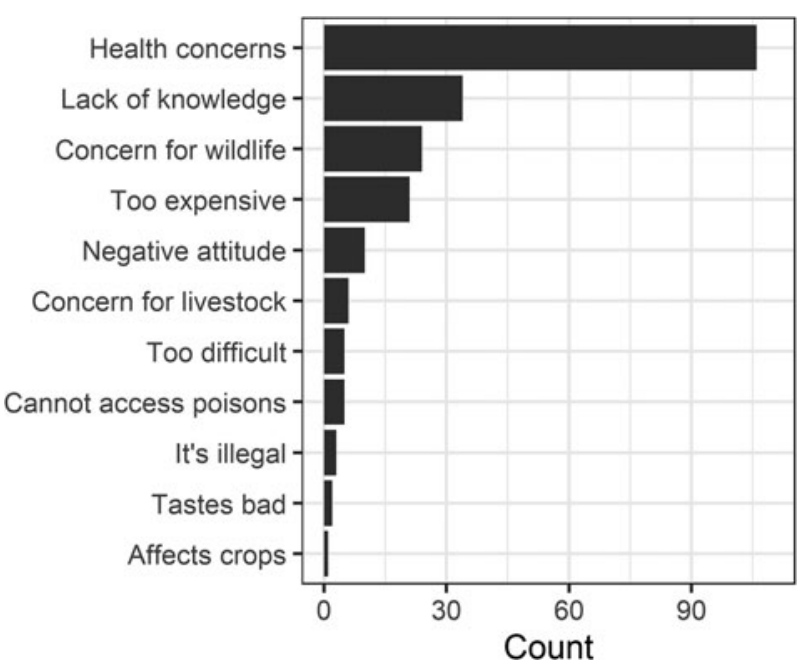

FIG. 6 Reasons given for not using poison, by 168 survey respondents who stated they hunt wildlife.

be a reason why conflict or sanctioning has rarely occurred. For example, in one focus group discussion participants believed that if a cow was poisoned it would not lead to an argument because they would be unable to identify the poisoner. An informant whose dog had been killed gave a similar explanation. The possibility of facing legal consequences was cited by four respondents across four villages, and by participants in two focus group discussions, as reason to conduct poisoning in secrecy. For example, one chief expected that most adults would phone the police if they saw children using poison. Another informant suggested that no one would talk to us about poisoning because of fear we would report them to the government. Nevertheless, among those who admitted hunting, legality was only offered as a reason not to use poison by three individuals
(2\%; Fig. 6). Among former poisoners, only one cited law enforcement as a reason for having stopped the practice.

In five villages, local authorities reported action to deter or punish poisoning, after receiving reports from members of the community or directly observing poisoning. Usually, members of community protected area committees observed these incidents when patrolling. The first response is a verbal warning, but they may also be referred to the village chief. One chief asked offenders to sign a contract, a common practice in Cambodia, promising to refrain from poisoning. Informants perceived that these individuallytargeted interventions were successful in deterring individual hunters from using poison again. For example, one community protected area chief claimed:

In 2013 we caught someone and brought him to the village chief. He had put a plastic bag in a hole in the waterhole and put a termite poison in [...]. If cattle had been poisoned, he would have to pay a big fine, but the [village] chief made him sign a contract [not to continue] and he has now stopped...

In three villages, preventive action had been taken at the community level. Two chiefs used village meetings to ask villagers not to use poison, and in one case also forbade shopkeepers from stocking the poison (although several informants indicated local stocks existed and a shopkeeper reacted angrily when we inquired). Another chief had referred the issue to the commune chief, following which environment authorities came to hold a similar meeting. This chief also expressed the expectation that a fine should be levied if a hunter was known to have poisoned cattle. However, wildlife poisoning continues, and this was acknowledged by the chiefs, for example:

The villagers are all unhappy [about poisoning] [...]. Last year I told everyone at a meeting to not do it and forbade the shopkeepers to sell the poison, [...] but people continue to do it in secret. 


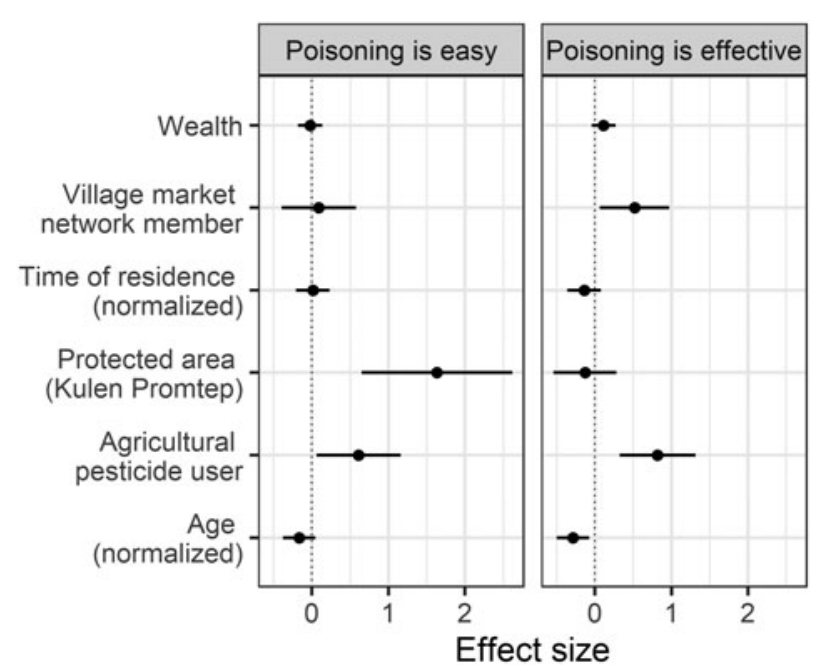

FIG. 7 We fit cumulative linked mixed models (logistic regressions), to examine which variables predict perceived behavioural control. The two Likert responses (poisoning is easy, and poisoning is effective) used to measure this construct were analysed separately. This figure shows the effect size for each variable, and the bars show the $95 \%$ confidence intervals.

\section{Discussion}

In northern Cambodia, wildlife is being poisoned by pesticides deposited near seasonal waterholes. We found that several practices and actors may be contributing to wildlife poisoning, but most significant is an intentional form of hunting carried out by local residents, particularly young men and children older than 12 years. Our study presents a first characterization of this practice using a mixed-methods approach, and quantifies its socio-psychological determinants using the theory of planned behaviour (Ajzen, 1991). Although we were unable to quantify the prevalence of poisoning, reports suggest that it was being practiced in eight of the 10 villages surveyed, and that it is affecting the environment, public health, livestock and wildlife. The pesticides used include carbamates, which are extremely toxic to birds (Richards, 2011), and placement at critical dry season water sources means that even low frequencies of poisoning may be having significant impacts on threatened bird species (Loveridge et al., 2019; Pin et al., 2020). For example, individuals of Critically Endangered species of vulture and ibis were reported to be affected. Further anecdotal evidence suggests these practices are occurring beyond our study area and they should be taken seriously by local and national authorities.

Some poisoning in Cambodia may be occurring as a symbolic and visible form of resistance to conservation rules (Norgrove \& Hulme, 2006; Essen \& Allen, 2017). This was suggested by one village chief in a community with a long-standing ecotourism project, where a waterhole had been poisoned close to the guest lodge. However, most poisoning occurs where visibility is low, and the low salience of conservation law enforcement among hunters and interviewees suggests this form of symbolic poisoning is a limited occurrence (Peterson et al., 2017). Most reports indicated that poisoning is predominantly a method of harvesting wild meat for household consumption. It is seen as an effective method that requires few skills and little effort, and is practised during the dry season, when other sources of meat are less available (Coad et al., 2019). Our data do not suggest a clear link with poverty or food insecurity as wealthier households were also implicated, and many poorer households expressed disapproval. Similarly, hunters using poison to whom we spoke directly did not raise food insecurity as a consideration in deciding whether or not to continue using poison. Nevertheless, it may play a role for some hunters.

Varying perceptions of the health risks associated with consuming poisoned meat seem to play a larger role. Among other hunters and former poisoners, health concerns were a prominent reason given for not using poison. But others downplayed these risks or believed that removing the internal organs rendered the meat safe. For them, the ability to catch meat with ease in the dry season outweighed the perceived health risks. This form of poisoning is unusual as most documented cases of wildlife poisoning are symbolic acts related to conflicts (Berny, 2007; Richards, 2011), but there are similarities with practices documented in Bunyala, Kenya, where carbofuran pesticides and baits are used to harvest wild birds at seasonal wetlands. Consumers there also believed that poisoned meat can be rendered safe, although in Cambodia, hunters consume the meat themselves, whereas in Kenya they supply markets (Odino, 2011).

Waterhole poisoning affects other members of the community (e.g. by harming cattle and dogs) and represents a risk to public health through distribution of contaminated meat and contamination of water sources used for drinking and washing, and fisheries. Concerns about these impacts have led some local authorities to sanction individual hunters or organize meetings to discourage further poisoning. These have taken place in villages where injunctive norms are more negative, either because the authorities' actions produced these negative norms or because authorities feel enabled to act where negative injunctive norms already exist. Whether these sanctions have had deterrent effects is unknown, but poisoning continues to occur. This suggests there are groups of villagers who consider poisoning acceptable and who are not influenced by the chief, and potentially that other influential villagers condone poisoning (perhaps implicitly) among their clients (Ledgerwood \& Vijghen, 2002). In other words, there are variable perceptions of social norms within different parts of the village social network (Shepherd, 2017), or as one chief articulated: 'they are not among my friends'. For example, younger respondents tended to have less negative norm perceptions, suggesting 
they may feel less constrained by village norms. This may also explain why informants gave diverging estimates of prevalence: either because they had access to different social information (i.e. they perceived it as common because their relatives all did it), or because they felt different social pressures to exaggerate or downplay poisoning in their responses to us. Our association with the chiefs may have played a role in this.

We did not record any reports of conflicts caused by poisoning. Some informants suggested that they simply do not know who is poisoning and so cannot do anything about it. Perhaps some are not aware that it occurs, particularly in villages where it has not yet had large negative impacts. Others were aware but chose to keep silent, as revealed by the actions of one informant who spoke freely in private, but not in a group setting. Many of the questions related to poisoning posed during group discussions were met with long silences. This culture of silence may have been towards us as outsiders, who potentially cannot be trusted and who might bring law enforcement or other consequences to the village, or to maintain the village's reputation (Nyumba et al., 2018). Law enforcement was cited by some as reason for secrecy, but only rarely cited as reason not to poison.

Alternatively, silence is maintained to preserve harmony within the community, or to avoid retribution. Khmer culture is conflict averse, but resentment can simmer before erupting violently (Luco, 2002). Data from one pilot village outside the protected areas provides a stark comparison, as poisoning was discussed openly, was widespread, and was perceived as legal. Perhaps the absence of conservation activity there meant villagers did not understand the illegality of their actions and were not concerned about legal sanction. But we also recorded no negative impacts on other villagers here, perhaps because there were social norms regulating where and how waterholes could be poisoned, which served to prevent conflict. For example, discussants knew to avoid fishing in poisoned waterholes. Similar dynamics may exist among some groups in the other villages, but perhaps involvement in conservation has precluded the possibility of these norms emerging at village level, as at least some elites will be interested in maintaining conservation programmes. Our study does not indicate how different networks and individuals, with different poisoning norms and behaviours, interact within a village, and how conservation may be producing anti-poisoning norms or resistance to these norms at different levels.

Our study highlights some methodological challenges in the study of sensitive behaviour. We applied the unmatched count technique to measure the prevalence of poisoning, but observed a design effect, suggesting respondents actively manipulated their responses to avoid implication of engagement in poisoning. Other unmatched count technique studies in Cambodia or on wildlife poisoning have encountered similar problems (Nuno \& St John, 2015; Fairbrass et al.,
2016; Ibbett et al., 2017). If the unmatched count technique is to become a widely applicable tool, more research will be needed into how respondents perceive the method, and how this varies across contexts (Hinsley et al., 2019). Other measured variables such as beliefs and attitudes may be equally susceptible to social desirability biases but lack specialized methods for measurement in sensitive cases. For example, individuals who have positive attitudes towards poisoning might disclose a negative attitude. Researchers should develop methods to measure complex sensitive variables that go beyond prevalence (but see Kramon \& Weghorst, 2019). An alternative is to use more in-depth ethnographic approaches to study the social dynamics in one place, but there is a trade-off between depth and generalizability. We chose in this study to gain a more superficial understanding of broad patterns over a landscape, as a prelude to gaining deeper understanding in fewer locations. Despite these limitations, our study nonetheless generated reliable insights into wildlife poisoning by using multiple complementary methods and triangulating qualitatively across a large number of data sources. The many informants across multiple communities giving similar descriptions of poisoning practices, motivations, actors and community perceptions gives confidence in these results. The neutral presentation of the research team was key to collecting these data (Drury et al., 2011). We have carried out a more in-depth study in one village that further supports our findings (de Lange et al., unpubl. data).

Our results could be used to guide the design of more effective interventions (Michie et al., 2008). Perceptions of health risks were a salient factor in decisions about poisoning. The approach employed in Bunyala, Kenya, focused on raising awareness about the risks of consuming poisoned meat, but this was unsuccessful as consumers had extensive personal experiences that supported their belief that risks were low (Wu \& Shaffer, 1987; Odino, 2011). We found similar beliefs in our study, but these could potentially be influenced by selecting appropriate messengers, such as local doctors (Pornpitakpan, 2004). Social norms can be a powerful motivator for behaviour change (Cialdini, 2015), so the anti-poisoning norms present in some places may be effective levers (McDonald et al., 2013). Interventions could increase the prominence of these norms and provide new avenues for villagers to apply social pressure on others in ways that avoid direct conflict. Conflict could have unintended negative consequences in this context, such as reinforcing poisoning as a norm within certain subgroups, or provoking poisoning as a form of resistance (Luco, 2002; Peterson et al., 2017). For this reason, commonly used normative interventions such as community discussions may be culturally inappropriate as they require open confrontation. Media dramatization could alternatively be used to provoke changes in normative perceptions (Bicchieri, 2017), and encouraging and rewarding public 
pledges (i.e. to use pesticides correctly, or to report poisoning) could facilitate strong normative signals and positive social incentives to engage (McKenzie-Mohr \& Schultz, 2014). One approach successfully trialled in Lao was implementing a hotline to facilitate anonymous reporting of hunting, and then providing public feedback on these reports (Saypanya et al., 2013). As a result, influential individuals might perceive that authorities are aware of the problem and that to continue condoning poisoning within their networks could jeopardize their position.

As children appear to be using poisons to hunt, interventions could encourage parents to be more vigilant by focusing on health risks, working with trusted messengers such as local schools. Because there is heterogeneity in use of poison between villages (Fig. 3), interventions could prioritize those where poisoning is more prevalent, tailored to the situation in each community. Where local chiefs have already acted against poisoning and strong anti-poisoning norms exist, interventions could be co-designed with these authorities. In other places where poisoning is less salient (i.e. villagers are less conscious of it), and norms are weaker, awarenessraising activities could be more impactful. Finally, enforcing existing pesticide regulations, and limiting the availability of restricted chemicals such as carbofurans should be a national priority.

Effectively addressing new conservation threats such as wildlife poisoning requires knowledge of behavioural drivers and social contexts (St John et al., 2013). For such sensitive behaviours, data collection can be challenging. Nevertheless, as our study shows, using multiple complementary methods and triangulating data allowed us to draw more reliable inferences. These findings can be used to select interventions that are likely to be more effective than those based on intuition or expert opinion (Cook et al., 2010). Robust testing and evaluation of the ensuing interventions will also be essential (Baylis et al., 2016) but, whether or not evaluation occurs, formative mixed-methods research, as carried out in this study, can play a valuable role in conservation interventions. As poisoning is potentially widespread and may have catastrophic impacts on wildlife, people, domestic animals and the environment, this issue should be prioritized by local and national authorities.

Acknowledgements We thank the Royal Government of Cambodia Ministry of Environment, Preah Vihear Department of Environment, and the Provincial Governor of Preah Vihear for facilitating this research; Alistair Mould, Simon Mahood, Ashish John, Rours Vann (rest in peace), Tong Sokha, Keo Sovanna, Uy Sitha, and others at the Wildlife Conservation Society Cambodia Programme for support and guidance; the village chiefs who hosted and supported us, especially Aum Rue; the respondents and participants; an anonymous reviewer; and Dona Sao for translating this article into Khmer. Permission for the research was given by the Ministry of Environment, the Provincial Governor's office, and each village chief. Credit for Fig. 1: Wildlife Conservation Society Cambodia. EdL was supported by a studentship from the UK Government Natural Environment Research Council E3
Doctoral Training Partnership (grant number NERC NE/L002558/1), and an Early Career Grant from the National Geographic Society.

Author contributions Study design: EdL, EJMG, AK, YV, LC; fieldwork: EdL, YV, LC; data analysis: EdL; writing: EdL, EJMG, AK, SP.

\section{Conflicts of interest None.}

Ethical standards This research was approved by the ethics committee of the School of Geosciences, University of Edinburgh (No. 191, 2017), and abided by the Oryx guidelines on ethical standards.

\section{References}

Ajzen, I. (1991) The theory of planned behavior. Orgnizational Behavior and Human Decision Processes, 50, 179-211.

Baylis, K., Honey-Rosés, J., Börner, J., Corbera, E., EzzineDe-Blas, D., Ferraro, P.J. et al. (2016) Mainstreaming impact evaluation in nature conservation. Conservation Letters, 9, 58-64.

Beauchamp, E., Clements, T. \& Milner-Gulland, E.J. (2018a) Assessing medium-term impacts of conservation interventions on local livelihoods in Northern Cambodia. World Development, 101, 202-218.

Beauchamp, E., Clements, T. \& Milner-Gulland, E.J. (2018b) Exploring trade-offs between development and conservation outcomes in Northern Cambodia. Land Use Policy, 71, 431-444.

Beauchamp, E., Woodhouse, E., Clements, T. \& MilnerGuLLAND, E.J. (2018c) 'Living a good life': conceptualizations of well-being in a conservation context in Cambodia. Ecology \& Society, 23, 28.

Beauchamp, E., Clements, T. \& Milner-Gulland, E.J. (2019) Investigating perceptions of land issues in a threatened landscape in northern Cambodia. Sustainability, 11, 5881.

Beban, A., Schoenberger, L., Lamb, V., Beban, A. \& Schoenberger, L. (2019) Pockets of liberal media in authoritarian regimes: what the crackdown on emancipatory spaces means for rural social movements in Cambodia. Journal of Peasant Studies, 47, 95-115.

Berny, P. (2007) Pesticides and the intoxication of wild animals. Journal of Veterinary Pharmacology and Therapeutics, 30, 93-100.

Bicchieri, C. (2017) Tools for change. In Norms in the Wild: How to Diagnose, Measure, and Change Social Norms. Chapter 4. Oxford University Press, New York, USA.

BIDdulPh, R. (2015) In whose name and in whose interests? An actor-oriented analysis of community forestry in Bey, a Khmer village in Northeast Cambodia. In Conservation and Development in Cambodia (eds S. Milne \& S. Mahanty), pp. 160-176. Routledge, Abingdon, UK.

BLAIR, G. \& IMAI, K. (2010) list: statistical methods for the item count technique and list experiment. R Archive Network. cran.r-project. org/package=list [accessed 18 February 2020].

BLAIR, G. \& IMAI, K. (2012) Statistical analysis of list experiments. Political Analysis, 20, 47-77.

Brunette, W., Sundt, M., Dell, N., Chaudhri, R., Breit, N. \& Borriello, G. (2013) Open Data Kit 2.o: expanding and refining information services for developing regions. HotMobile '13: Proceedings of the 14th Workshop on Mobile Computing Systems and Applications, February 2013, article no. 10.

Buechley, E.R. \& ŞEKerCioĞLU, Ç.H. (2016) The avian scavenger crisis: looming extinctions, trophic cascades, and loss of critical ecosystem functions. Biological Conservation, 198, 220-228.

Carson, R. (1962) Silent Spring. Houghton Mifflin, New York, USA. 
Cialdini, R.B. (2015) Crafting normative messages to protect the environment. Current Directions in Psychological Science, 12, 105-109.

Clements, T. \& Milner-Gulland, E.J. (2015) Impact of payments for environmental services and protected areas on local livelihoods and forest conservation in northern Cambodia. Conservation Biology, 29, 78-87.

Clements, T., John, A., Nielsen, K., An, D., Tan, S. \& Milner-Gulland, E.J. (2010) Payments for biodiversity conservation in the context of weak institutions: comparison of three programs from Cambodia. Ecological Economics, 69, 1283-1291.

Coad, L., Lim, S. \& Nuon, L. (2019) Wildlife and livelihoods in the Cardamom Mountains, Cambodia. Frontiers in Ecology and Evolution, 7, 296

Cook, C.N., Hockings, M. \& Carter, R.W. (Bill) (2010) Conservation in the dark? The information used to support management decisions. Frontiers in Ecology and the Environment, $8,181-186$

Craig, D. \& Kimchoeun, P. (2011) Party financing of local investment projects. In Cambodia's Economic Transformation (eds C. Hughes \& K. Un), pp. 219-244. Nordic Institute of Asian Studies, Copenhagen, Denmark.

Davis, K.F., Yu, K., Rulli, M.C., Pichdara, L. \& D’Odorico, P. (2015) Accelerated deforestation driven by large-scale land acquisitions in Cambodia. Nature Geoscience, 8, 772-775.

Delisle, A., Kiatkoski Kim, M., Stoeckl, N., Watkin Lui, F. \& Marsh, H. (2018) The socio-cultural benefits and costs of the traditional hunting of dugongs Dugong dugon and green turtles Chelonia mydas in Torres Strait, Australia. Oryx, 52, 250-261.

Drury, R., Homewood, K. \& Randall, S. (2011) Less is more: the potential of qualitative approaches in conservation research. Animal Conservation, 14, 18-24.

EJF (Environmental Justice Foundation) (2002) Death in Small Doses: Cambodia's Pest Problems and Solutions. Environmental Justice Foundation, London, UK.

Essen, E. \& Allen, M. (2017) Interspecies violence and crimes of dissent: communication ethics and legitimacy in message. Critical Criminology, 25, 261-274.

Fairbrass, A., Nuno, A., Bunnefeld, N. \& Milner-Gulland, E.J. (2016) Investigating determinants of compliance with wildlife protection laws: bird persecution in Portugal. European Journal of Wildlife Research, 62, 93-101.

Hardemn, W., Johnston, M., Johnston, D., Bonetti, D., Wareham, N. \& Kinmonth, A.L. (2002) Application of the Theory of Planned Behaviour in behaviour change interventions: a systematic review. Psychology \& Health, 17, 123-158.

Hinsley, A., Keane, A.M., St John, F.A.V., Iвbett, H. \& Nuno, A. (2019) Asking sensitive questions using the unmatched count technique: applications and guidelines for conservation. Methods in Ecology and Evolution, 10, 308-319.

Hughes, C. \& UN, K. (2011) Cambodia's economic transformation: historical and theoretical frameworks. In Cambodia's Economic Transformation (eds C. Hughes \& K. Un), pp. 1-26. Nordic Institute of Asian Studies, Copenhagen, Denmark.

Ibbett, H., Lay, C., Phlai, P., Song, D., Hong, C., Mahood, S.P. \& Milner-Gulland, E.J. (2017) Conserving a globally threatened species in a semi-natural, agrarian landscape. Oryx, 53, 181-191.

Ibbett, H., Keane, A., Dobson, A., Griffin, O., Travers, H. \& Milner-Gulland, E.J. (2020) Estimating hunting prevalence and reliance on wild meat in Cambodia's Eastern Plains. Oryx, published online 23 October 2020.

Jones, S., Keane, A., St John, F.A.V., Vickery, J. \& Papworth, S. (2019) Audience segmentation to improve targeting of conservation interventions for hunters. Conservation Biology, 33, 895-905.
Kramon, E. \& Weghorst, K. (2019) (Mis)Measuring sensitive attitudes with the list experiment: solutions to list experiment breakdown in Kenya. Public Opinion Quarterly, 83, 236-263.

Ledgerwood, J. \& Vijghen, J. (2002) Decision making in rural Khmer villages. In Cambodia Emerges From the Past: Eight Essays (ed. J. Ledgerwood). Southeast Asia Publications, Center for Southeast Asian Studies, Northern Illinois University, Dekalb, USA.

Loveridge, R., Ryan, G.E., Sum, P., Grey-Read, O., Mahood, S.P., Mould, A. et al. (2019) Poisoning causing the decline in South-east Asia's largest vulture population. Bird Conservation International, 29, 41-54.

LuCO, F. (2002) Between a Tiger and a Crocodile. Management of Local Conflicts in Cambodia: An Anthropological Approach to Traditional and New Practices. UNESCO, Phnom Penh, Cambodia.

Matsukawa, M., Ito, K., Kawakita, K. \& Tanaka, T. (2016) Current status of pesticide use among rice farmers in Cambodia. Applied Entomology and Zoology, 51, 571-579.

McDonald, R.I., Fielding, K.S. \& Louis, W.R. (2013) Energizing and de-motivating effects of norm-conflict. Personality and Social Psychology Bulletin, 39, 57-72.

Mckenzie-Mohr, D. (2000) Promoting sustainable behavior: an introduction to community-based social marketing. Journal of Social Issues, 56, 543-554.

McKenzie-Mohr, D. \& Schultz, P.W. (2014) Choosing effective behavior change tools. Social Marketing Quarterly, 20, 35-46.

Michie, S., Johnston, M., Francis, J., Hardeman, W. \& ECCles, M. (2008) From theory to intervention: mapping theoretically derived behavioural determinants to behaviour change techniques. Applied Psychology, 57, 660-68o.

Milne, S. (2015a) Cambodia's unofficial regime of extraction: illicit logging in the shadow of transnational governance and investment. Critical Asian Studies, 47, 200-228.

Milner-Gulland, E.J., Bennett, E.L., Abernethy, K., Bakarr, M., Bennett, E., Bodmer, R. et al. (2003) Wild meat: the bigger picture. Trends in Ecology and Evolution, 18, 351-357.

Morgenbesser, L. (2019) Cambodia's transition to hegemonic authoritarianism. Journal of Democracy, 30, 158-171.

Myers, N., Mittermeier, R.A., Mittermeier, C.G., Fonseca, G.A.B.D. \& KenT, J. (2000) Biodiversity hotspots for conservation priorities. Nature, 403, 853-858.

Norgrove, L. \& Hulme, D. (2006) Confronting conservation at Mount Elgon, Uganda. Development and Change, 37, 1093-1116.

Nuno, A. \& ST John, F.A.V. (2015) How to ask sensitive questions in conservation: a review of specialized questioning techniques. Biological Conservation, 189, 5-15.

Nyumba, T.O., Wilson, K., Derrick, C.J. \& Mukherjee, N. (2018) The use of focus group discussion methodology: insights from two decades of application in conservation. Methods in Ecology and Evolution, 9, 20-32.

Odino, M. (2011) Measuring the conservation threat that deliberate poisoning poses to birds in Kenya: the case of pesticide hunting with Furadan in the Bunyala Rice Irrigation Scheme. In Carbofuran and Wildlife Poisoning: Global Perspectives and Forensic Approaches (ed. N. Richards), pp. 53-69. Wiley-Blackwell, Hoboken, USA.

OGADA, D.L. (2014) The power of poison: pesticide poisoning of Africa's wildlife. Annals of the New York Academy of Sciences, 1322, 1-20.

Ogada, D., Bотнa, A. \& Shaw, P. (2016) Ivory poachers and poison: drivers of Africa's declining vulture populations. Oryx, 50, 593-596.

Ovesen, J., Trankell, I.-B. \& Ojendal, J. (1996) When Every Household is an Island: Social Organization and Power Structures in Rural Cambodia. Department of Cultural Anthropology, Uppsala University, Uppsala, Sweden. 
Peterson, M.N., von Essen, E. \& Hansen, H.P. (2017) Illegal fishing and hunting as resistance to neoliberal colonialism. Crime, Law, and Social Change, 67, 401-413.

Petroczi, A., Nespusz, T., Cross, P., Taft, H., Shah, S., Deshmukh, N. et al. (2011) New non-randomised model to assess the prevalence of discrimination behaviour: a pilot study on mephedrone. Substance Abuse Treatment, Prevention, and Policy, 6, 1-18.

Pin, C., Ngoprasert, D., Gray, T.N.E., Savini, T., Crouthers, R. \& GaLE, G.A. (2020) Utilization of waterholes by globally threatened species in deciduous dipterocarp forest of the Eastern Plains Landscape of Cambodia. Oryx, 54, 572-582.

Pornpitakpan, C. (2004) The persuasiveness of source credibility: a critical review of five decades evidence. Journal of Applied Social Psychology, 34, 243-281.

QSR InTERNATIONAL (2015) NVivo. QSR International. qsrinternational.com/nvivo/home [accessed 18 February 2020].

R Core TeAm (2017) R: a language and environment for statistical computing. R Foundation for Statistical Computing, Vienna, Austria. r-project.org [accessed 18 February 2020].

Richards, N. (2011) Carbofuran and Wildlife Poisoning: Global Perspectives and Forensic Approaches. Wiley-Blackwell, Chichester, UK.

Rotterdam Convention (2013) Cambodia. pic.int/Countries/ CountryProfiles [accessed 18 February 2020].

Royal Government of Cambodia (2012) Law on the Management of Pesticides and Fertilizers. cambodiantr.gov.kh/kcfinder/upload/ files/Law\%20on\%2oManagement\%20of\%2oPesticides\%2oand\% 2oFertilizers\%20-\%20EN.pdf [accessed 23 June 2020].

Saroeun, B. (1999) Pesticides Killing Great Lake. The Phnom Penh Post Issue 8-10 14-27th May. Phnom Penh, Cambodia.

Saypanya, S., Hansel, T., Johnson, A., Bianchessi, A. \& SADOWSKY, B. (2013) Effectiveness of a social marketing strategy, coupled with law enforcement, to conserve tigers and their prey in Nam Et Phou Louey National Protected Area, Lao People's Democratic Republic. Conservation Evidence, 10, 57-66.

SEDARA, K. (2011) Reciprocity: informal patterns of social interaction in a Cambodian village. In Anthropology and Community in Cambodia (ed. J.A. Marston), pp. 153-170. Monash University Press, Clayton, Australia.

Shepherd, H.R. (2017) The structure of perception: how networks shape ideas of norms. Sociological Forum, 32, 72-93.

ST John, F.A.V., Edwards-Jones, G. \& Jones, J.P.G. (2010) Conservation and human behaviour: lessons from social psychology. Wildlife Research, 37, 658-667.

St John, F.A.V., Keane, A.M. \& Milner-Gulland, E.J. (2013) Effective conservation depends upon understanding human behaviour. In Key Topics in Conservation Biology 2 (eds D.W. Macdonald \& K.J. Willis), pp. 344-361. John Wiley \& Sons, Hoboken, USA.

Travers, H., Clements, T., Keane, A.M. \& Milner-Gulland, E.J. (2011) Incentives for cooperation: the effects of institutional controls on common pool resource extraction in Cambodia. Ecological Economics, 71, 151-161.

Travers, H., Archer, L.J., Mwedde, G., Roe, D., Baker, J., Plumptre, A. et al. (2019) Understanding complex drivers of wildlife crime to design effective conservation interventions. Conservation Biology, 33, 1296-1306.

Ward, C., Holmes, G. \& Stringer, L. (2018) Perceived barriers to and drivers of community participation in protected-area governance. Conservation Biology, 32, 437-446.

Wildife Conservation Society (2016) Carbofuran Poisoning at the Interface Between Wildife, Livestock, and Humans. Wildlife Conservation Society Cambodia, Phnom Penh, Cambodia.

Wu, C. \& Shaffer, D.R. (1987) Susceptibility to persuasive appeals as a function of source credibility and prior experience with the attitude object. Journal of Personality and Social Psychology, 52, 677-688. 